\title{
Eating habits associated with a history of suicide attempts in psychiatric outpatients
}

\author{
Cosme Alvarado-Esquivel ${ }^{1^{*}}$, Jesús Hernández-Tinoco² ${ }^{2}$ Luis Francisco Sánchez-Anguiano², \\ Carlos Alberto Arnaud-Gil ${ }^{3}$, Luis Fernando Molina-Espinoza ${ }^{3}$ \\ ${ }^{1}$ Biomedical Research Laboratory, Faculty of Medicine and Nutrition, Juárez University of Durango State, Durango, Mexico; \\ *Corresponding Author: alvaradocosme@yahoo.com \\ ${ }^{2}$ Institute for Scientific Research “Dr. Roberto Rivera Damm”, Juárez University of Durango State, Durango, Mexico \\ ${ }^{3}$ Hospital of Mental Health "Dr. Miguel Vallebueno”, Secretary of Health, Durango, Mexico
}

Received 7 December 2013; revised 9 January 2014; accepted 18 January 2014

Copyright (C 2014 Cosme Alvarado-Esquivel et al. This is an open access article distributed under the Creative Commons Attribution License, which permits unrestricted use, distribution, and reproduction in any medium, provided the original work is properly cited. In accordance of the Creative Commons Attribution License all Copyrights (c) 2014 are reserved for SCIRP and the owner of the intellectual property Cosme Alvarado-Esquivel et al. All Copyright (C 2014 are guarded by law and by SCIRP as a guardian.

\section{ABSTRACT}

Background: The association of eating habits and suicide attempts has been insufficiently studied. Aim: This study aimed to determine the eating habits associated with suicide attempts in a sample of psychiatric outpatients. Methods: Through a case control study design, 283 psychiatric outpatients attending in two public hospitals in Durango City, Mexico were studied. Of the 283 patients, 156 have had suicide attempts and 127 have not had suicide attempts. Eating habits were obtained from all outpatients and compared in patients with history of suicide attempts and patients without such history. Results: Logistic regression analysis showed differences in eating habits between psychiatric outpatients with and without history of suicide attempts. A history of suicide attempts was positively associated with consumption of pork (OR $=2.35,95 \% \mathrm{Cl}: 1.17-4.71 ; P=0.01)$, mutton (OR $=2.38,95 \% \mathrm{Cl}: 1.25-4.52 ; P=0.008)$, chorizo $(\mathrm{OR}=2.09,95 \% \mathrm{Cl}$ : $1.04-4.19 ; P=0.03)$, unwashed raw vegetables $(\mathrm{OR}=3.23,95 \% \mathrm{Cl}$ : $1.26-8.32 ; P=0.01)$, and untreated water $(\mathrm{OR}=$ $1.77,95 \% \mathrm{Cl}: 1.03-3.02 ; P=0.03$ ), and negatively associated with consumption of goat meat $(\mathrm{OR}=0.39,95 \% \mathrm{Cl}: 0.17-0.90 ; P=0.02)$, and turkey meat $(\mathrm{OR}=0.41,95 \% \mathrm{Cl}: 0.23-0.73 ; P=$ 0.002). Conclusions: This is the first report on the association of eating habits with suicide attempts in psychiatric outpatients. Results suggest that suicide attempts are associated not only with the type of meat consumed but also with poor food hygiene in psychiatric outpatients. Further studies to confirm or challenge such results are needed.

\section{KEYWORDS}

Epidemiology; Case-Control Study; Suicide Attempts; Psychiatric Patients; Eating Habits; Mexico

\section{INTRODUCTION}

Suicidal behavior is an important contributing factor for injury and death all around the world [1,2]. The frequency of suicidal behavior among populations is similar in both developed and developing countries [3]. The lifetime prevalence of suicide attempts in populations among countries is $2.7 \%$ [1]. In Mexico, the suicide rate has risen [4], and $65.2 \%$ of persons who have had a suicide attempt had a prior diagnosis of a psychiatric disorder [5]. Therefore, psychiatric patients are an important group of population for the study of suicide attempts. A number of epidemiological characteristics in populations have been associated with suicide attempts including socio-demographic, behavioral and clinical factors [6-10]. However, very little is known about the association of suicide attempts with eating habits. In the Third National Health and Nutrition Examination Survey in the USA, researchers found that fruits, vegetables and meat were underconsumed in adults with a history of suicide attempt [11]. In addition, in the Mexican National Health and Nutrition Survey 2006, researchers found an association between suicide attempts and disordered eating behaviors in adolescents [12]. Epidemiological studies to determine 
the association of eating habits and suicide attempts would help find new predictors for suicide attempts and design preventive measures against suicide attempts. Therefore, this study aimed to determine the relation of eating habits with suicide attempts in psychiatric outpatients.

\section{METHODS}

\subsection{Study Design and Study Population}

Two hundred eighty three psychiatric outpatients were enrolled in this case control study from September 2011 to June 2012 in Durango City, Mexico. One hundred fifty six of whom had suicide attempt history (cases) and 127 outpatients had no history of suicide attempts (controls). Sampling of cases and controls was performed randomly among outpatients attended for consultations in two public hospitals (Hospital of Mental Health "Miguel Vallebueno" and the General Hospital) of the Secretary of Health. All outpatients were aged 18 years and older. Gender and psychiatric diagnosis were not restrictive criteria for enrollment. Cases outpatients included 119 females and 37 males aged 18 - 61 years old (mean $34.01+/-10.25$ years). Control outpatients included 76 females and 51 males aged 18 - 69 years old (mean 38.26 $+/-11.62$ years). Public hospitals of the Secretary of Health in Durango City attend mostly low income people. Therefore, a low socioeconomic status was predominant in the outpatients included in the study.

\subsection{Ethical Aspects}

The purpose and procedures of the study were explained to all outpatients, and a written informed consent was obtained from each participant. Participation of the outpatients was voluntary. This study was approved by both the Ethical Committee of the Hospital of Mental Health "Dr. Miguel Vallebueno" of the Secretary of Health in Durango City and the Ethical Committee of the General Hospital of the Secretary of Health in Durango City, Mexico.

\subsection{Eating Habits of Outpatients}

Information about eating habits of outpatients was obtained with the aid of a standardized questionnaire. Eating habits explored: 1) meat consumption (pork, beef, goat, sheep, boar, chicken, turkey, pigeon, rabbit, venison, squirrel, horse, opossum, or other); 2) degree of meat cooking; 3) consumption of dried or cured meat (ham, sausages, salami or chorizo); chorizo consumed in Durango, Mexico is a red fresh sausage made mostly of raw pork tissues mixed with raw chili pepper; 4) frequency of eating out of home (at restaurants and fast food outlets); 5) consumption of unwashed raw vegetables, fruits, untreated water, or unpasteurized milk.

\subsection{Statistical Analysis}

The statistical analyses were performed with the aid of the software Epi Info version 3.5.4 and SPSS 15.0 (SPSS Inc. Chicago, Illinois, USA). To evaluate the difference in the frequencies between the groups, the Pearson's chi-square test or Fisher exact test (when the sample was 5 or less) were used. Bivariate and multivariate analyses were used to evaluate the association between the eating habits of the outpatients and suicide attempts. Variables were included in the multivariate analysis if they had a $P$ value equal to or less than 0.20 in the bivariate analysis. Odds ratios (OR) and 95\% confidence intervals (CI) were calculated by multivariate analysis using the Enter method. A $P$ value less than 0.05 was considered statistically significant.

\section{RESULTS}

Bivariate analysis showed a number of eating habits related with suicide attempters (Table 1). Eating habits positively associated with suicide attempts included consumption of pork ( $P=0.001)$, chorizo $(P=0.007)$, unwashed raw vegetables $(P=0.002)$, unwashed raw fruits ( $P=0.03)$, and untreated water $(P=0.007)$. Eating habits negatively associated with suicide attempters included consumption of goat meat $(P=0.02)$, and turkey meat $(P=0.01)$. Other eating habits explored in outpatients did not show any significant association with suicide attempts by bivariate analysis (Table 1). Further analysis by gender of the patients showed a positive association of consumption of pork with suicide attempts in both females $(P=0.01)$ and males $(P=0.03)$. In addition, a positive association of suicide attempts and consumption of unwashed raw vegetables $(P=0.001)$ and fruits $(P=0.03)$, and untreated water $(P=0.001)$ was found in female patients but not in male patients. Other eating habits were not associated with suicide attempts in the groups of women or men. Further analysis by age groups (18 - 30, 31 - 50, and 51 - 71 years old) showed a positive association of suicide attempts with consumption of pork $(P=0.03)$, mutton $(P=0.03)$, and untreated water $(P=0.006)$ in the age group of $31-50$ years but not in younger or older subjects. In addition, a negative association of suicide attempts with consumption of goat meat $(P=0.04)$ was found in the age group of 18 - 30 years but not in older subjects. Other eating habits were not associated with suicide attempts in the age groups.

Logistic regression analysis of eating habits with a $P$ value equal to or less than 0.20 (Table 2) showed that a history of suicide attempts was positively associated with consumption of pork $(\mathrm{OR}=2.35,95 \% \mathrm{CI}: 1.17-4.71$; $P$ $=0.01)$, mutton $(\mathrm{OR}=2.38,95 \% \mathrm{CI}: 1.25-4.52 ; P=$ 
Table 1. Bivariate analysis of eating habits and their relation with suicide attempters.

\begin{tabular}{|c|c|c|c|c|c|c|}
\hline \multirow[b]{2}{*}{ Habit } & \multirow{2}{*}{$\begin{array}{c}\text { No. of patients } \\
\text { examined }^{*}\end{array}$} & \multicolumn{2}{|c|}{ Suicide attempters } & \multirow{2}{*}{$\begin{array}{l}\text { Odds } \\
\text { ratio }\end{array}$} & \multirow{2}{*}{$\begin{array}{c}\text { 95\% Confidence } \\
\text { interval }\end{array}$} & \multirow{2}{*}{$\begin{array}{c}P \\
\text { value }\end{array}$} \\
\hline & & No. & $\%$ & & & \\
\hline \multicolumn{7}{|c|}{ Frequency of meat consumption } \\
\hline Less than 1 day a week & 34 & 17 & 50 & 1.00 & & \\
\hline 1 to 3 days a week & 197 & 110 & 55.8 & 1.26 & $0.58-2.78$ & 0.52 \\
\hline 4 to 7 days a week & 51 & 28 & 54.9 & 1.22 & $0.47-3.18$ & 0.65 \\
\hline \multicolumn{7}{|l|}{ Degree of meat cooking } \\
\hline Well done & 268 & 147 & 54.9 & 1.00 & & \\
\hline \multicolumn{7}{|l|}{ Ever eaten raw meat } \\
\hline Yes & 31 & 17 & 54.8 & 0.99 & $0.44-2.23$ & 0.97 \\
\hline No & 252 & 139 & 55.2 & 1.00 & & \\
\hline \multicolumn{7}{|l|}{ Ever eaten dried raw meat } \\
\hline Yes & 113 & 62 & 54.9 & 0.98 & $0.59-1.63$ & 0.93 \\
\hline \multicolumn{7}{|l|}{ Consumption of } \\
\hline \multicolumn{7}{|l|}{ Pork } \\
\hline Yes & 228 & 136 & 59.6 & 2.59 & $1.35-4.98$ & 0.001 \\
\hline No & 55 & 20 & 36.4 & 1.00 & & \\
\hline \multicolumn{7}{|l|}{ Beef } \\
\hline Yes & 276 & 152 & 55.1 & 0.92 & $0.16-4.97$ & 0.91 \\
\hline No & 7 & 4 & 57.1 & 1.00 & & \\
\hline \multicolumn{7}{|l|}{ Goat meat } \\
\hline Yes & 41 & 16 & 39 & 0.47 & $0.22-0.96$ & 0.02 \\
\hline No & 242 & 140 & 57.9 & 1.00 & & \\
\hline \multicolumn{7}{|l|}{ Mutton } \\
\hline Yes & 104 & 63 & 60.6 & 1.42 & $0.85-2.39$ & 0.15 \\
\hline No & 179 & 93 & 52 & 1.00 & & \\
\hline \multicolumn{7}{|l|}{ Boar meat } \\
\hline No & 271 & 152 & 56 & 1.00 & & \\
\hline \multicolumn{7}{|l|}{ Chicken meat } \\
\hline Yes & 272 & 148 & 54.4 & 0.51 & $0.10-2.25$ & 0.26 \\
\hline No & 10 & 7 & 70 & 1.00 & & \\
\hline \multicolumn{7}{|l|}{ Turkey meat } \\
\hline Yes & 142 & 68 & 47.9 & 0.55 & $0.33-0.91$ & 0.01 \\
\hline No & 141 & 88 & 62.4 & 1.00 & & \\
\hline Pigeon meat & & & & & & \\
\hline Yes & 14 & 8 & 57.1 & 1.09 & $0.33-3.65$ & 0.87 \\
\hline No & 269 & 148 & 55 & 1.00 & & \\
\hline Rabbit meat & & & & & & \\
\hline Yes & 33 & 20 & 60.6 & 1.29 & $0.58-2.89$ & 0.5 \\
\hline No & 250 & 136 & 54.4 & 1.00 & & \\
\hline Venison & & & & & & \\
\hline Yes & 40 & 21 & 52.5 & 0.88 & $0.43-1.82$ & 0.71 \\
\hline No & 243 & 135 & 55.6 & 1.00 & & \\
\hline Squirrel meat & & & & & & \\
\hline Yes & 11 & 3 & 27.3 & 0.29 & $0.06-1.24$ & 0.05 \\
\hline No & 272 & 153 & 56.3 & 1.00 & & \\
\hline Horse meat & & & & & & \\
\hline Yes & 8 & 2 & 25 & 0.26 & $0.04-1.47$ & 0.08 \\
\hline No & 275 & 154 & 56 & 1.00 & & \\
\hline Opossum meat & & & & & & \\
\hline Yes & 1 & 1 & 100 & - & - & 0.55 \\
\hline No & 282 & 155 & 55 & 1.00 & & \\
\hline Other meat & & & & & & \\
\hline
\end{tabular}




\section{Continued}

\begin{tabular}{|c|c|c|c|c|c|c|}
\hline Yes & 26 & 14 & 53.8 & 0.93 & $0.39-2.24$ & 0.85 \\
\hline No & 255 & 142 & 55.7 & 1.00 & & \\
\hline \multicolumn{7}{|c|}{ Chorizo consumption } \\
\hline Yes & 225 & 133 & 59.1 & 2.20 & $1.17-4.14$ & 0.007 \\
\hline No & 58 & 23 & 39.7 & 1.00 & & \\
\hline \multicolumn{7}{|c|}{ Raw cow milk } \\
\hline Yes & 101 & 52 & 51.5 & 0.80 & $0.47-1.34$ & 0.35 \\
\hline No & 182 & 104 & 57.1 & 1.00 & & \\
\hline \multicolumn{7}{|c|}{ Raw goat milk } \\
\hline Yes & 9 & 7 & 77.8 & 2.94 & $0.55-20.84$ & 0.14 \\
\hline No & 274 & 149 & 54.4 & 1.00 & & \\
\hline \multicolumn{7}{|c|}{ Unwashed raw vegetables } \\
\hline Yes & 59 & 43 & 72.9 & 2.64 & $1.35-5.22$ & 0.002 \\
\hline No & 224 & 113 & 50.4 & 1.00 & & \\
\hline \multicolumn{7}{|c|}{ Unwashed raw fruits } \\
\hline Yes & 92 & 59 & 64.1 & 1.73 & $1.01-2.99$ & 0.03 \\
\hline No & 191 & 97 & 50.8 & 1.00 & & \\
\hline \multicolumn{7}{|c|}{ Untreated water } \\
\hline Yes & 162 & 100 & 61.7 & 1.91 & $1.15-3.17$ & 0.007 \\
\hline No & 120 & 55 & 45.8 & 1.00 & & \\
\hline \multicolumn{7}{|c|}{ Eating out of home } \\
\hline Yes & 249 & 139 & 55.8 & 1.26 & $0.58-2.74$ & 0.52 \\
\hline No & 34 & 17 & 50 & 1.00 & & \\
\hline
\end{tabular}

*Patients with available data.

Table 2. Results of the multivariate regression analysis.

\begin{tabular}{cccc}
\hline & & Odds & 95\% Confidence \\
\hline Variable & $P$ value & ratio & interval \\
\hline Consumption of: & & & \\
Pork & 0.01 & 2.35 & $1.17-4.71$ \\
Goat meat & 0.02 & 0.39 & $0.17-0.90$ \\
Mutton & 0.008 & 2.38 & $1.25-4.52$ \\
Boar meat & 0.06 & 0.24 & $0.05-1.10$ \\
Turkey meat & 0.002 & 0.41 & $0.23-0.73$ \\
Squirrel meat & 0.05 & 0.2 & $0.04-1.01$ \\
Horse meat & 0.14 & 0.21 & $0.02-1.68$ \\
Chorizo & 0.03 & 2.09 & $1.04-4.19$ \\
Raw goat milk & 0.17 & 4.57 & $0.49-42.07$ \\
Unwashed raw vegetables & 0.01 & 3.23 & $1.26-8.32$ \\
Unwashed raw fruits & 0.73 & 1.14 & $0.53-2.46$ \\
Untreated water & 0.03 & 1.77 & $1.03-3.02$ \\
\hline
\end{tabular}

0.008), chorizo (OR $=2.09,95 \% \mathrm{CI}: 1.04-4.19 ; P=$ $0.03)$, unwashed raw vegetables (OR $=3.23$, 95\% CI: 1.26 - 8.32; $P=0.01)$, and untreated water $(\mathrm{OR}=1.77$, 95\% CI: 1.03 - 3.02; $P=0.03)$, and negatively associated with consumption of goat meat $(\mathrm{OR}=0.39$, 95\% CI: $0.17-0.90 ; P=0.02)$, and turkey meat (OR $=0.41,95 \%$ CI: $0.23-0.73 ; P=0.002)$. Other eating habits explored were not associated with suicide attempts by multivariate analysis (Table 2).

\section{DISCUSSION}

In this work several eating habits in psychiatric outpatients were found associated with a history of suicide attempts. Multivariate analysis showed that consumption of pork, mutton, chorizo, unwashed raw vegetables, and untreated water was positively associated with a history of suicide attempts in psychiatric outpatients. On the other hand, multivariate analysis showed that consumption of goat and turkey meats was negatively associated with a history of suicide attempts. Results suggest that suicide attempters had eating habits different from nonattempters. Concerning the meat variables, history of suicide attempts was not related with the frequency of eating meat or the cooking habits but with the type of meat consumed. It is not clear why consumption of a particular type of meat is positively or negatively associated with suicide attempts. To the best of our knowledge, there are not any reports of such associations in the medical literature. There is only one previous study that reported an association of suicide attempts history with eating habits. In the Third National Health and Nutrition Examination Survey in the USA, Li et al. [11] found that fruits, vegetables and meat were significantly underconsumed in adults aged 17 - 39 years with suicide attempts history. Results of the present work support the existence of differences in eating habits among suicide 
attempters and non-attempters reported in the USA national survey, but do not support the association of suicide attempts history with a low consumption of meat [11]. In the present study, the frequency of suicide attempters was similar among outpatients eating meat less than once a week than those eating meat from 1 to 3 times a week or from 4 to 7 times a week. Differences in such results between the studies might be explained by differences in the studied populations. In the current work psychiatric outpatients were studied, while general population was studied in the national survey. There are only few reports about the correlation of eating habits and psychiatric disorders. Food and eating have been related with affective disorders [13]. Changes in eating have been found in patients suffering from dementia including increased and decreased food intake, altered food choice, the consumption of inedible substances and disturbances in the process of eating [14]. In a study in Switzerland, female patients suffering from seasonal affective disorder consumed carbohydrate-rich foods more often than controls [15]. In addition, female patients with seasonal affective disorder selectively ate sweets under emotionally difficult conditions [16]. In a Mexican study, suicide attempts were associated with disordered eating behaviors in adolescents [12]. Furthermore, results of diet-related laboratory tests have shown links between eating habits and suicide behavior. A low cholesterol level has been linked with an increased risk of suicide [17]. A history of attempted suicide was also associated with low levels of antioxidant vitamins and carotenoids in adults enrolled in the Third National Health and Nutrition Examination survey in the USA [18].

With respect to the association of history of suicide attempts with consumption of unwashed raw vegetables and untreated water, such results point towards poor food hygiene practices in suicide attempters. The poor hygiene practices may lead to infections in suicide attempters. In fact, suicide attempts have been associated with Toxoplasma gondii infection [19,20]. Pork is a wellknown potential source of $T$. gondii infection [21-23], and consumption of such meat (pork and chorizo) was associated with history of suicide attempts in the present study. It is tempting to speculate that there might be an infectious factor either Toxoplasma gondii or another pathogen causing food-borne infections related with suicide behaviors. Apart from the infectious hypothesis, it is also possible that the particular eating habits in suicide attempters just reflect a particular life-style behavior in such group of psychiatric patients. Although suicide behaviors are multifactorial, results suggest that eating habits may play a contributing role in suicide attempts.

This is the first report of the association of eating habits with suicide attempts in psychiatric outpatients. Results suggest that suicide attempts are associated not only with the type of meat consumed but also with poor food hygiene in psychiatric outpatients. Further studies to confirm or challenge such results are needed.

\section{REFERENCES}

[1] Nock, M.K., Borges, G., Bromet, E.J., Cha, C.B., Kessler, R.C. and Lee, S. (2008) Suicide and suicidal behavior. Epidemiologic Reviews, 30, 133-154. http://dx.doi.org/10.1093/epirev/mxn002

[2] Grzywa, A., Kucmin, A. and Kucmin, T. (2010) Suicide problems-Epidemiology, factors, motives and prevention. Part II. Polski Merkuriusz Lekarski, 28, 174-176.

[3] Borges, G., Nock, M.K., Haro-Abad, J.M., Hwang, I., Sampson, N.A., Alonso, J. andrade, L.H., Angermeyer, M.C., Beautrais, A., Bromet, E., Bruffaerts, R., de Girolamo, G., Florescu, S., Gureje, O., Hu, C., Karam, E.G., Kovess-Masfety, V., Lee, S., Levinson, D., Medina-Mora, M.E., Ormel, J., Posada-Villa, J., Sagar, R., Tomov, T., Uda, H., Williams, D.R. and Kessler, R.C. (2010a) Twelve-month prevalence of and risk factors for suicide attempts in the World Health Organization World Mental Health Surveys. Journal of Clinical Psychiatry, 71, 16171628. http://dx.doi.org/10.4088/JCP.08m04967blu

[4] Borges, G., Orozco, R., Benjet, C. and Medina-Mora, M.E. (2010b) Suicide and suicidal behaviors in Mexico: Retrospective and current status. Salud Pública de México, 52, 292-304.

[5] Borges, G., Nock, M.K., Medina-Mora, M.E., Hwang, I. and Kessler, R.C. (2010c) Psychiatric disorders, comorbidity and suicidality in Mexico. Journal of Affective Disorders, 124, 98-107.

[6] Nock, M.K., Borges, G., Bromet, E.J., Alonso, J., Angermeyer, M., Beautrais, A., Bruffaerts, R., Chiu, W.T., de Girolamo, G., Gluzman, S., de Graaf, R., Gureje, O., Haro, J.M., Huang, Y., Karam, E., Kessler, R.C., Lepine, J.P., Levinson, D., Medina-Mora, M.E., Ono, Y., Posada-Villa, J. and Williams, D. (2008b) Cross-national prevalence and risk factors for suicidal ideation, plans and attempts. The British Journal of Psychiatry, 192, 98-105. http://dx.doi.org/10.1192/bjp.bp.107.040113

[7] Bi, B., Tong, J., Liu, L., Wei, S., Li, H., Hou, J., Tan, S., Chen, X., Chen, W., Jia, X., Liu, Y., Dong, G., Qin, X. and Phillips, M.R. (2010) Comparison of patients with and without mental disorders treated for suicide attempts in the emergency departments of four general hospitals in Shenyang, China. General Hospital Psychiatry, 32, 549555.

http://dx.doi.org/10.1016/j.genhosppsych.2010.06.003

[8] Turhan, E., Inandi, T., Aslan, M. and Zeren, C. (2011) Epidemiology of attempted suicide in Hatay, Turkey. Neurosciences (Riyadh), 16, 347-352.

[9] Li, Y., Li, Y. and Cao, J. (2012) Factors associated with suicidal behaviors in mainland China: A meta-analysis. BMC Public Health, 12, 524. http://dx.doi.org/10.1186/1471-2458-12-524

[10] Christiansen, E., Larsen, K.J., Agerbo, E., Bilenberg, N. and Stenager, E. (2013) Incidence and risk factors for 
suicide attempts in a general population of young people: A Danish register-based study. Australian \& New Zealand Journal of Psychiatry, 47, 259-270. http://dx.doi.org/10.1177/0004867412463737

[11] Li, Y., Zhang, J. and McKeown, R.E. (2009) Cross-sectional assessment of diet quality in individuals with a lifetime history of attempted suicide. Psychiatry Research, 165, 111-119. http://dx.doi.org/10.1016/j.psychres.2007.09.004

[12] Palma-Coca, O., Hernández-Serrato, M.I., VillalobosHernández, A., Unikel-Santoncini, C., Olaiz-Fernández, G. and Bojorquez-Chapela, I. (2011) Association of socioeconomic status, problem behaviors and disordered eating in Mexican adolescents: Results of the Mexican National Health and Nutrition Survey 2006. Journal of Adolescent Health, 49, 400-406. http://dx.doi.org/10.1016/j.jadohealth.2011.01.019

[13] Wallin, M.S. and Rissanen, A.M. (1994) Food and mood: Relationship between food, serotonin and affective disorders. Acta Psychiatrica Scandinavica, 377, 36-40. http://dx.doi.org/10.1111/j.1600-0447.1994.tb05800.x

[14] Morris, C.H., Hope, R.A. and Fairburn, C.G. (1989) Eating habits in dementia. A descriptive study. The British Journal of Psychiatry, 154, 801-806. http://dx.doi.org/10.1192/bjp.154.6.801

[15] Kräuchi, K. and Wirz-Justice, A. (1988) The four seasons: Food intake frequency in seasonal affective disorder in the course of a year. Psychiatry Research, 25, 323-338. http://dx.doi.org/10.1016/0165-1781(88)90102-3

[16] Kräuchi, K., Reich, S. and Wirz-Justice, A. (1997) Eating style in seasonal affective disorder: Who will gain weight in winter? Comprehensive Psychiatry, 38, 80-87. http://dx.doi.org/10.1016/S0010-440X(97)90085-7

[17] Zhang, J. (2011) Epidemiological link between low cholesterol and suicidality: A puzzle never finished. Nutri- tional Neuroscience, 14, 268-287. http://dx.doi.org/10.1179/1476830511Y.0000000021

[18] Li, Y. and Zhang, J. (2007) Serum concentrations of antioxidant vitamins and carotenoids are low in individuals with a history of attempted suicide. Nutritional Neuroscience, 10, 51-58.

http://dx.doi.org/10.1080/10284150701250747

[19] Arling, T.A., Yolken, R.H., Lapidus, M., Langenberg, P., Dickerson, F.B., Zimmerman, S.A., Balis, T., Cabassa, J.A., Scrandis, D.A., Tonelli, L.H. and Postolache TT. (2009) Toxoplasma gondii antibody titers and history of suicide attempts in patients with recurrent mood disorders. The Journal of Nervous and Mental Disease, 197, 905908. http://dx.doi.org/10.1097/NMD.0b013e3181c29a23

[20] Ling, V.J., Lester, D., Mortensen, P.B., Langenberg, P.W. and Postolache, T.T. (2011) Toxoplasma gondii seropositivity and suicide rates in women. The Journal of Nervous and Mental Disease, 199, 440-444. http://dx.doi.org/10.1097/NMD.0b013e318221416e

[21] Jones, J.L. and Dubey, J.P. (2012) Foodborne toxoplasmosis. Clinical Infectious Diseases, 55, 845-851. http://dx.doi.org/10.1093/cid/cis508

[22] Alvarado-Esquivel, C., García-Machado, C., AlvaradoEsquivel, D., González-Salazar, A.M., Briones-Fraire, C., Vitela-Corrales, J., Villena, I. and Dubey, J.P. (2011) Seroprevalence of Toxoplasma gondii infection in domestic pigs in Durango State, Mexico. Journal of Parasitology, 97, 616-619. http://dx.doi.org/10.1645/GE-2755.1

[23] Alvarado-Esquivel, C., Estrada-Malacón, M.A., ReyesHernández, S.O., Pérez-Ramírez, J.A., Trujillo-López, J.I., Villena, I. and Dubey, J.P. (2012) High prevalence of Toxoplasma gondii antibodies in domestic pigs in Oaxaca State, Mexico. Journal of Parasitology, 98, 1248-1250. http://dx.doi.org/10.1645/GE-3184.1 